\title{
Behavioral Consequences of a Bifacial Map in the Mouse Somatosensory Cortex
}

\author{
Vassiliy Tsytsarev, ${ }^{1 \star}$ Hiroyuki Arakawa, ${ }^{1 \star}$ Shuxin Zhao, ${ }^{1}{ }^{\oplus A l a i n}$ Chédotal, ${ }^{2}$ and ${ }^{\circledR R e h a ~ S . ~ E r z u r u m l u ~}{ }^{1}$ \\ ${ }^{1}$ Department of Anatomy and Neurobiology, University of Maryland School of Medicine, Baltimore, Maryland 21201, and ${ }^{2}$ Centre de Recherche Institut de \\ la Vision, Institut National de la Santé et de la Recherche Médicale, Unité Mixte de Recherche S968, 75012 Paris, France
}

The whisker system is an important sensory organ with extensive neural representations in the brain of the mouse. Patterned neural modules (barrelettes) in the ipsilateral principal sensory nucleus of the trigeminal nerve (PrV) correspond to the whiskers. Axons of the PrV barrelette neurons cross the midline and confer the whisker-related patterning to the contralateral ventroposteromedial nucleus of the thalamus, and subsequently to the cortex. In this way, specific neural modules called barreloids and barrels in the contralateral thalamus and cortex represent each whisker. Partial midline crossing of the PrV axons, in a conditional Robo3 mutant $\left(R o b o 3^{R 3-5} c K O\right)$ mouse line, leads to the formation of bilateral whisker maps in the ventroposteromedial, as well as the barrel cortex. We used voltagesensitive dye optical imaging and somatosensory and motor behavioral tests to characterize the consequences of bifacial maps in the thalamocortical system. Voltage-sensitive dye optical imaging verified functional, bilateral whisker representation in the barrel cortex and activation of distinct cortical loci following ipsilateral and contralateral stimulation of the specific whiskers. The mutant animals were comparable with the control animals in sensorimotor tests. However, they showed noticeable deficits in all of the whisker-dependent or -related tests, including Y-maze exploration, horizontal surface approach, bridge crossing, gap crossing, texture discrimination, floating in water, and whisking laterality. Our results indicate that bifacial maps along the thalamocortical system do not offer a functional advantage. Instead, they lead to impairments, possibly due to the smaller size of the whisker-related modules and interference between the ipsilateral and contralateral whisker representations in the same thalamus and cortex.

Key words: barrel cortex; barreloids; midline crossing defects; optical imaging; Robo3; whisker-sensitive behaviors

\section{Significance Statement}

The whisker sensory system plays a quintessentially important role in exploratory behavior of mice and other nocturnal rodents. Here, we studied a novel mutant mouse line, in which the projections from the brainstem to the thalamus are disrupted. This led to formation of bilateral whisker maps in both the thalamus and the cortex. The two whisker maps crowd in a space normally devoted to the contralateral map alone and in a nonoverlapping fashion. Stimulation of the whiskers on either side activates the corresponding region of the map. Mice with bilateral whisker maps perform well in general sensorimotor tasks but show poor performance in specific tests that require whisker-dependent tactile discrimination. These observations indicate that contralateral, instead of bilateral, representation of the sensory space plays a critical role in acuity and fine discrimination during somesthesis.

\section{Introduction}

A conspicuous feature of the primary sensory brain areas is the formation of a neural map of the sensory periphery. Sensory

Received March 3, 2017; revised June 14, 2017; accepted June 19, 2017.

Author contributions: V.T., H.A., A.C., and R.S.E. designed research; V.T., H.A., and S.Z. performed research; A.C. contributed unpublished reagents/analytic tools; V.T., H.A., and R.S.E. analyzed data;V.T., H.A., and R.S.E. wrote the paper.

This work was supported by Agence Nationale de la Recherche Grant ANR-14-CE13-0004-01 to A.C. and National Institutes of Health/National Institute of Neurological Disorders and Stroke Grant R01NS084818 to R.S.E. We thank P. Gaspar for critical comments on the manuscript; K. Arakawa for help with the colony management and genotyping; and B. Okura, K. Tsubokura, and T. Sakuraba for help with imaging.

The authors declare no competing financial interests.

*V.T. and H.A. contributed equally to this study.

Correspondence should be addressed to Dr. R.S. Erzurumlu, Department of Anatomy and Neurobiology, 20 maps of the retina, cochlea, and the somatic sensory space develop early in perinatal development and show critical period plasticity. Understanding the mechanisms of wiring and plasticity of these maps in both neonatal and adult states is a major endeavor in neuroscience. Experimental manipulations of developing sensory pathways and genetic mutations reveal the mechanisms underlying map formation and map plasticity.

\footnotetext{
Penn Street, HSFII-S251, University of Maryland School of Medicine, Baltimore, MD 21210. E-mail: rerzurumlu@som.umaryland.edu.

H. Arakawa's present address: Rodent Behavior Core, School of Medicine, Case Western Reserve University, Cleveland, $0 \mathrm{H} 44106$.

DOI:10.1523/JNEUROSCI.0598-17.2017

Copyright $\odot 2017$ the authors $\quad 0270-6474 / 17 / 377209-10 \$ 15.00 / 0$
} 
The mouse whisker system is an exquisite tactile organ, essential to construction of the perceptual world and exploratory behaviors of this species. At various levels of the mouse brain, discrete neural modules represent the orderly array of whisker follicles on the snout. Trigeminal ganglion axons, bridging the sensory periphery to the brainstem, convey whisker-specific patterns to the ventral portion of the trigeminal principal sensory nucleus (PrV). Here, neuronal aggregates, termed barrelettes, pattern after the spatial arrangement of the whiskers on the snout (Ma and Woolsey, 1984). The two caudally located subnuclei of the spinal trigeminal nucleus also develop whisker barrelettes. However, they do not contribute to the whisker-specific patterning downstream of the trigeminal brainstem (Killackey and Fleming, 1985; Erzurumlu and Ebner, 1988; Chiaia et al., 1991; Iwasato et al., 1997).

PrV projection neurons send their axons across the midline and reach the contralateral ventroposteromedial nucleus (VPM) of the thalamus. Here, too, whisker-specific neural modules develop, and they are called barreloids (Van der Loos, 1976). Barreloid neurons, in turn, convey the pattern template to layer IV of the primary somatosensory, or the barrel cortex (Woolsey and Van der Loos, 1970; Erzurumlu and Jhaveri, 1990). Thus, due to midline crossing of the PrV trigeminothalamic projections, the patterned maps in the thalamus and cortex represent contralateral whiskers.

During embryonic development, attractive and repulsive axon guidance cues govern the contralaterality of the trigeminothalamic projections. Midline guidance cues, such as netrin and slits, play major roles in temporally regulating axon attraction and repulsion (Chédotal, 2011; Izzi and Charron, 2011; Nawabi and Castellani, 2011; Friocourt and Chédotal, 2017). The PrV axons express receptors for slits and netrins; mutations that affect their expression lead to aberrant development of their projections (Mirza et al., 2013).

The PrV barrelette neurons are largely derived from rhombomere 3 (r3) (Oury et al., 2006; for review, see Erzurumlu et al., 2010; Bechara et al., 2015). The Krox20/Egr2 gene, which encodes a zinc finger transcription factor, was required for the development of $\mathrm{r} 3$ and $\mathrm{r} 5$ (Schneider-Maunoury et al., 1993). Conditional mutation of the Robo3 receptor, using the Krox20 promoter in mice (Krox $20^{\mathrm{Cre}}$; Robo3 ${ }^{l o x / l o x}$, named Robo $\left.3^{R 3-5} \mathrm{CKO}\right)$, results in disrupted midline crossing of the PrV trigeminothalamic axons. This midline crossing defect leads to the formation of bilateral whisker maps in the VPM and in the barrel cortex (Renier et al., 2017). Barreletteforming parts of the spinal trigeminal nucleus and the dorsal column nuclei are caudal to r3-r5, and their efferents are not affected.

In $R o b o 3^{R 3-5} c K O$ mice, bilateral whisker inputs segregate into well-defined territories, both in the thalamus and in the cortex. Interestingly, the area devoted to the face map does not alter in size or orientation, but instead, houses almost double the number of barrels (Renier et al., 2017). The total whisker representation areas in the thalamus and cortex do not change, perhaps because the sensory epithelium in the periphery has not changed and some of the PrV neurons that normally project to the contralateral thalamus now project ipsilaterally.

Because whiskers and barrels play major roles in the perceptual and behavioral repertoire of mice, we sought to determine whether having bilateral whisker representations and increased numbers of barrels in each thalamus and cortex would be advantageous for somesthesis. With this objective in mind, we assessed the general sensorimotor abilities, overall somatic sensory discrimination, whisker-specific sensory discrimination, and social behaviors of the mutant mice. We expected that bilateral whisker representation in a nonoverlapping fashion would increase discriminative capability. Instead, we found that this was not the case, most likely due to the smaller size of the whisker representing modules and potential interference between the two face maps.

\section{Materials and Methods}

Animals. A.C. provided the founders of the $\mathrm{Robo}^{R 3-5} \mathrm{CKO}$ mice, and we established a breeding colony at the University of Maryland Baltimore, School of Medicine in an Association for Assessment and Accreditation of Laboratory Animal Care-accredited laboratory facility. In a recent report Renier et al. (2017) described in detail, generation of the mutants, and whisker-related patterns along their trigeminal somatosensory pathway. We determined the genotypes by PCR from tail lysate DNA samples. We used Robo $3^{\text {lox } / l o x}$ and $\mathrm{Krox} 20^{\mathrm{Cr}} ; \mathrm{Robo}^{\mathrm{lox} /+}$-named $\mathrm{Robo} 3^{\mathrm{R3}-5-\mathrm{Het}}$ ) mice as controls. We found that there were no differences between these two genotypes and also compared with the C57BL/6J (http://jaxmice.jax. org/strain/013636.html; RRID:IMSR JAX:000664) line that we routinely use in morphological, functional and behavioral assays.

We performed all animal procedures were performed according to the regulations of the University of Maryland Baltimore School of Medicine Institutional Animal Care and Use Committee and the National Institute of Health Guide for the care and use of laboratory animals.

Histological confirmation of the bifacial maps in the somatosensory thalamus and cortex. We performed vesicular glutamate transporter 1 (VGLUT-1) and VGLUT-2 immuno- and cytochrome oxidase (CO) histochemistry in aldehyde-fixed brain sections to confirm and visualize the presence of bilateral whisker maps in $R o b o 3^{R 3-5} c K O$ mice (both sexes, $n=12$ ). The immunostaining for glutamate transporters and CO histochemistry are routine markers for whisker-specific patterns in the rodent brain.

We removed the neocortex from each brain and flattened them between glass slides. We sectioned flattened cortical specimens at $50 \mu \mathrm{m}$ thickness on a vibratome (Leica 1000S). We split the remaining brain tissue at the level of the midbrain. We sectioned the diencephalic pieces at an oblique horizontal plane and the remaining brainstem sections at the coronal plane. After several rinses in phosphate buffer, we incubated the free-floating sections in antibody solutions at $4^{\circ} \mathrm{C}$ for $48 \mathrm{~h}$. We performed immunostaining using guinea pig polyclonal antibodies against VGLUT-1 and VGLUT-2 from EMD Millipore (catalog \#AB5905 RRID: AB_2301751, catalog \#AB2251 RRID:AB_1587626). We used VGLUT-2 (1:500) for thalamocortical afferent terminals in the barrel cortex and trigeminothalamic afferents in the thalamus and VGLUT-1 (1:500) for the trigeminal afferents in the PrV. After we washed the primary antibodies from the sections, we applied fluorescent secondary antibodies (FITC-conjugated donkey anti guinea pig, 1:80, from Jackson ImmunoResearch Laboratories, code 706-545-148) for $1.5 \mathrm{~h}$. Afterward, we rinsed the sections in phosphate buffer several times and then mounted them onto glass slides and coverslipped them.

For CO histochemistry, we incubated flattened cortex sections in cytochrome $\mathrm{C}$ solution made up with $\mathrm{PBS}$ with diaminobenzidine, until the sections turned golden brown in color (Arakawa et al., 2014b).

We examined the immunostained sections under epifluorescence and $\mathrm{CO}$-stained sections under light field illumination and photographed regions of interest.

Voltage-sensitive dye optical imaging. We imaged the barrel cortex of Robo $3^{\text {R3-5 }} \mathrm{CKO}(n=6)$ and control (Robo3 $\left.3^{\text {R3-5-Het }}, n=6\right)$ male and female mice at 4-9 weeks of age using the MiCAM02 system (Brain Vision). After applying urethane anesthesia ( $1.15 \mathrm{~g} / \mathrm{kg}$ body weight $)$ and shaving their heads, we placed individual mice into a stereotaxic frame (Stoelting). We made a $3 \times 3 \mathrm{~mm}$ cranial opening over the left parietal cortex. We used hemostatic sponges dipped in ACSF to clean the exposed surface. Next, we applied voltage-sensitive dye RH-1691 (Optical Imaging; $2.0 \mathrm{mg} / \mathrm{ml}$ in ACSF) for $1 \mathrm{~h}$., and washed afterward with ACSF for 15 min (Tsytsarev et al., 2010; Lo et al., 2013). We covered the exposed area with high-density silicone oil and a $0.1-\mathrm{mm}$-thick coverslip.

We positioned the area to be imaged below the objective of the imaging system with its optical axis perpendicular to the cortical surface. The 
focusing plane was adjusted to the depth of $300 \mu \mathrm{m}$ below the dura mater. At the start of each imaging session, we obtained a grayscale image of the recording area.

Before the experiment, all of the whiskers, except the whiskers to be stimulated, were clipped close to the skin. At the start of each optical imaging session, a grayscale image of the dural surface was obtained and saved as a graphic file. Each experiment consisted of 100 trials, 500 frames per trial, with the stimulus (whisker deflection) presented at the 250th frame, 1 trial per stimulus. The intertrial interval was $12 \mathrm{~s}$. Change in fluorescence was calculated as F/F using the BrainVision Analyzer.

For the whisker stimulation, a glass capillary $(1.0 \mathrm{~mm}$ in diameter $)$ fitted onto an XYZ manipulator was aimed at the single, intact whisker. We applied air-puff of $10 \mathrm{~ms}$ duration through Picospritzer pressure valve connected to the glass capillary. The MiCAM02 imaging system controlled the Picospritzer, so that the whisker stimulation and changes in fluorescence signals could be synchronized. After data collection, we generated pseudocolor maps using first frame analysis and then averaged the data for each session (Ferezou et al., 2006; Tsytsarev et al., 2010).

Behavioral tests. Our histological and voltage-sensitive dye imaging (VSDi) data verified the presence of bifacial whisker maps at both the morphological level and the functional level. Next, we investigated the behavioral repertoire of the mutant mice to assess the consequences of bilateral whisker maps along the thalamocortical system. In this vein, we tested general sensorimotor abilities, overall somatic sensory discrimination, whisker-specific sensory discrimination, and social behaviors.

We used 9- to 12-week-old mice for behavioral testing in comparisons between Robo ${ }^{l o x / l o x}$ as a control and $R o b o 3^{R 3-5} \mathrm{cKO}$. Unlike the morphology and the imaging experiments, we used only male mice in behavioral tests, for the following reasons: (1) we did not find sex differences in several of the somatosensorimotor tests in a developmental study on C57BL/6 mice (Arakawa and Erzurumlu, 2015); (2) to keep in line with our previous behavioral studies in other mutant lines with whisker-barrel pattern defects (Arakawa et al., 2014a, b); and (3) one of the tests (social behavior) depends on the "resident-intruder" paradigm that is based on male behavior.

To avoid nonspecific behavioral reduction by general habituation with repeated test sessions, we separated the mice into two groups (Group 1: control and Robo $3^{R 3-5} \mathrm{CKO}$, each $n=9$; and Group 2: each $n=8$ ). We assigned Group 1 to a set of behavioral tests, including open field, social interaction, object recognition, Y-maze, bridge crossing, swimming, adhesive removal, and whisking tests. We assigned Group 2 to the remaining tests. The mice were housed 3-5 animals per cage in standard filter-top cages with access to water and rodent chow at all times, maintained on a 12:12 h light/dark cycle $\left(06: 00-18: 00 \mathrm{~h}\right.$ lighting) at $21^{\circ} \mathrm{C}$, and relative humidity of $50 \%-60 \%$. For each session, we moved the mice to the behavioral testing room and left them undisturbed for half an hour before the tests. We tested small groups of mice in tandem (Crawley, 2008) and ran three cohorts of mice at three separate times. Each test for individual mice took place with at least $1 \mathrm{~h}$ intervals. Notably, we performed the testing and subsequent analyses in an investigator blind fashion with respect to the mouse genotypes. Finally, our sample size for behavioral studies has a $90 \%$ power of detecting genotype differences at a 5\% two-tailed significance level.

Previously, we used most of the aforementioned tests to assess the behavioral consequences of genetic deletion of NMDA receptor and adenylate cyclase Type I function in mice (Arakawa et al., 2014a, b), and in developing and adult mice after whisker clipping (Arakawa and Erzurumlu, 2015). In this study, we conducted the following behavioral tests:

Wire grip test. This test is used as a measure of forelimb strength and coordination of movements to support the body weight (Crawley, 1999; Deacon, 2013). Instead of a horizontal bar, commonly used in this test, we used the wire top lid of a standard mouse cage. Because of this, we taped the hindpaws of the mice so that they only use their forelimbs. The mice used their forepaws to suspend their body from a single wire of the wire-top cage lid. We recorded the mean time (in seconds) of suspension (or the latency of dropping to the cage floor), in three trials per session. A maximum cutoff latency of $60 \mathrm{~s}$ was recorded if the mouse did not drop to the cage. We took the average time in three trials as a representative value for each mouse.

Adhesive removal test. We selected the adhesive removal test (Komotar et al., 2007; Bouet et al., 2009) to assess dorsal column-lemniscal sensitivity. We placed an adhesive-backed label $(0.5 \mathrm{~cm}$ square $)$ on the palmar side of the hindpaw and recorded the latency of the first reaction to the stimulus (sniffing, paw lifting, biting, and removal of the label). We performed the test in the home cage.

$Y$ maze spontaneous alternation test. This test is based on the innate preference of mice to alternate arms of a Y- or T-maze while exploring this new environment. The test is most commonly used as a test for hippocampal, prefrontal cortex functions (Wolf et al., 2016). Because whisker sensation is a major perceptual device for rodents in exploring their environment, we used this test here to compare the behaviors of Robo ${ }^{R 3-5} \mathrm{CKO}$ mice with that of the controls. The animal is introduced to one arm of the Y-shaped maze (arm length: $35 \mathrm{~cm}$, width: $8 \mathrm{~cm}$, height: $15 \mathrm{~cm}$ ) and the test lasts until the mouse makes 20 arm choices. We then recorded the number of entries and the sequence of entries to calculate the percentage of alternation.

Open field test. In general, this test is used to evaluate locomotion, exploratory behavior, anxiety, and general activity levels of rodent subjects, especially following various experimental manipulations or drug treatments (Mothes et al., 1996; Saitoh et al., 2014). We used this test as whisking is an essential component of the mouse exploratory behavior. The open-field apparatus was a clear Plexiglas arena $(28 \times 26 \times 18$ [height] $\mathrm{cm}$ ), illuminated by a small red lamp. The floor of the chamber was line-marked into equal size quadrants. After placing the individual mice in the center of the field, we recorded the freely moving mice for 5 min to measure the number of line crossings. We also scored stretchattend postures as an additional exploratory behavior (Rodgers and Dalvi, 1997; Blanchard et al., 2003).

Social behavior test. The resident-intruder paradigm is a standard test for measuring social investigation and live performance for social behaviors, including intermale aggression and social defeat in rodents (Koolhaas et al., 2013). Here, we used it as a metric for social behavior, without priming the resident for aggression or introducing an aggressive intruder. We conducted this test following the open-field test. We kept the mice in the chamber after the open-field test and introduced an "intruder" male mouse (C57BL/6 strain) into the chamber. The behaviors of the mice, videotaped during a $10 \mathrm{~min}$ session, included the duration of the contacts when the subject mouse approached the intruder and events of flight responses to the approaches. We calculated the ratio of appearances for flight responses to the intruder's approaches from the front or back of the body.

Horizontal surface approach test. This test is based on the postural reflex and limb placement when mice are suspended by their tail and are approaching a surface that they can reach with their forepaws (Gerlai et al., 2000). We picked up individual mice by the tail and slowly moved horizontally toward the edge of a desk with $1 \mathrm{~cm} / 5 \mathrm{~s}$ speed. Mice used their whiskers to detect and touch the surface edge as fast as they could. We repeated the procedure four times. We measured the distance (in centimeters) of the body position from the edge of the platform when the mice were able to reach it with the forepaws. We calculated the average of the distances in four trials was calculated as a representative value.

Bridge crossing test. This test (also known as raised beam test) is generally used for testing motor coordination (Brooks and Dunnett, 2009). Mice are placed on an end of a bridge ( $4 \mathrm{~cm}$ width, $25 \mathrm{~cm}$ length) leading to a box platform in a dark container under infrared lighting. The animals cross the bridge to reach the platform by using whiskers to sense the bridge edges. We performed three trials per mouse and the maximum cutoff time was $90 \mathrm{~s}$. We used the traverse time (in seconds) as measurements.

Swimming test. Mice use their whiskers to maintain balance while floating in water. When placed in water, whisker-clipped mice and "barrelless," adenylate cyclase Type 1-deficient mice show similar levels of struggling and paddling, compared with wild-type mice, but their floating ratio decreases significantly (Arakawa et al., 2014a). We placed individual mice in a $2 \mathrm{~L}$ Pyrex glass beaker containing $1.8 \mathrm{~L}$ of water (maintained at $24 \pm 1^{\circ} \mathrm{C}$ ) for $5 \mathrm{~min}$. We videotaped their performances 
and analyzed swimming, including paddling and floating without paddling.

Measures of whisking behavior. Videotaping of whisking behavior (with a high-speed camera, EX-FH100, Casio, at $120 \mathrm{fps}$ ), as mice freely move or approach objects provides measures of exploratory and active whisking behaviors. We placed a small, clear glass cup in the cage sideways and allowed the mouse to explore inside and around the cup. Next, we placed other small objects (e.g., a toothbrush or a plastic cup) in the cage and recorded the whisking behavior of the animal. We analyzed the frequencies and the types of whisking toward the objects.

Gap-crossing test. The gap-crossing test was developed to test cortical whisker barrel function (Hutson and Masterton, 1986; Barnéoud et al., 1991). The test consists of a series of trials requiring the mouse to cross a gap in a bridge with variable distances. We placed the subjects in the center of an elevated lane ( $4 \mathrm{~cm}$ diameter) connected to a platform. The gap distance between the lane and the platform varied from 0 to $8 \mathrm{~cm}$ by $1 \mathrm{~cm}$ increments. We measured the gap distance (in centimeters) that the mice were able to cross to get to the safe platform. We performed the trials under infrared lighting so that the mice relied on tactile rather than visual cues.

Object discrimination test. Mice have an innate preference to spend more time exploring the novel objects that they encounter. This particular test relies on this preference. We conducted three trials in the home cage under low lighting, and mice were able to see the objects in their cage. During the first trial, we placed two identical objects (plastic Easter eggs) at opposite corners of the cage, and the mouse was allowed to explore the objects for $5 \mathrm{~min}$. After a $1 \mathrm{~h}$ interval, we ran the second trial, in which a new object was placed in the cage along with one of the familiar objects from the first trial in the same location. The new object was a small pot, glass cup, toothbrush, or D-type battery. After another $1 \mathrm{~h}$ interval, in the third trial, we placed one familiar object and a new object in the cage. The order of the objects was counterbalanced for each animal. We measured the time spent in investigating each object and calculated the preference for novel objects as a discrimination measure.

Texture discrimination test. We conducted this test in the same way as the object discrimination test but in the dark (without visual cues); also, the objects that we placed in the cage had surfaces made of different textures. The objects were plastic cups filled with materials of different textures, such as sponge, metal mesh, terry cloth, cardboard, etc.).

Whisking laterality test. This test is specifically developed for the Robo $3^{R 3-5} C K O$ mice in our laboratory to examine left-right whisking preference at objects encountered on the left or the right side of the snout. The test apparatus is a bridge between two platforms. Along the sides of the bridge six stainless steel thin rods, 3 on each side are vertically positioned $3 \mathrm{~cm}$ away from the center of the bridge. The test is conducted under infrared light. We position the mouse on one platform and the mouse crosses to the other platform through the bridge encountering the rods with its whiskers along the way. When the animal's whiskers contact a rod, they orient their snout to the rod to investigate further by active whisking. We videotaped whisking behavior and quantified the occurrence of whisker contact with a rod and orientation of the snout to the rod are. Orientation of the snout with respect to the rod is also noted in three categories: ipsilateral, when the mouse whisks at the rod with the whiskers on the side of the rod; medial, when the snout is oriented to the rod and the animal whisks with whiskers on both sides of the snout; and contralateral, when the animal turns its head and whisks with whiskers on the side contralateral to the position of the rod (i.e., if the rod is on the left side of the mouse and the animal whisks the right snout).

Statistical analysis. Our experimental design was random. We used one-way or two-way ANOVA for the statistical analysis. We used the Bonferroni correction for the post hoc comparisons when necessary. For pair-comparison in behavioral tests $\left(R o b o^{l o x / l o x}\right.$ vs $R o b o 3^{R 3-5} \mathrm{CKO}$ ), we used the unpaired Student's $t$ test when datasets with equal variances, while the Welch's $t$ test was used with unequal variances. For all tests, differences were accepted as significant at $p<0.05$. All data are expressed as mean \pm SEM.
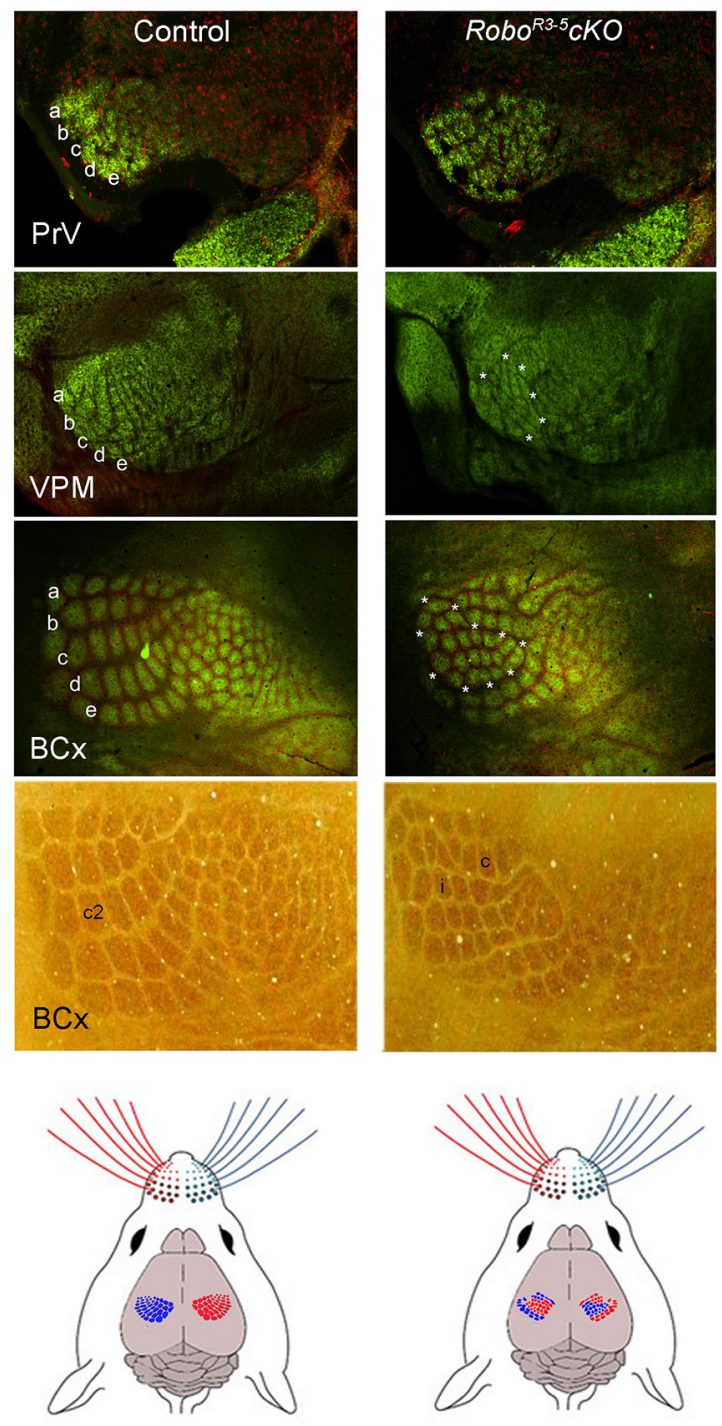

Figure 1. Patterning of the whisker-barrel pathway in $R 0 b 03^{R 3-5} \mathrm{CKO}$ mice. Glutamate transporter immunohistochemistry reveals afferent terminal patterns that correspond to barrelettes in the PrV, barreloids in the VPM nucleus, and barrels in the cortex (BCX). Left column photomicrographs represent normal patterning in control animals at successive levels of the trigeminal neuraxis. Right column photomicrographs represent photomicrographs in Robo $3^{R 3-5} \mathrm{CKO}$ mice at successive levels of the trigeminal neuraxis. Although barrelette patterns in the principal sensory nucleus are normal, there is aberrant patterning in the VPM and in the barrel cortex $(B C x)$. In the immunostained mutant barrel cortex, asterisks indicate the boundary of the ipsilateral map. Whisker barrel rows are indicated in the control cortex. CO-stained sections shown in the bottom micrographs further illustrate the smaller size of the barrels in the $R 0 b 03^{R 3-5} \mathrm{CKO}$ cortex. C2 whisker is indicated and the approximate locations of the ipsilateral (i) and contralateral (c) $\mathrm{C} 2$ whisker barrels in the Robo $3^{R 3-5} \mathrm{CKO}$ cortex section are marked. Bottom diagrams illustrate the ipsilateral and contralateral whisker representations in the barrel cortex of normal (left) and mutant (right) mice.

\section{Results}

Immunohistochemistry for glutamate transporters and CO histochemistry confirmed the presence of bilateral whisker representations in the VPM and the barrel cortex of $R o b o 3^{R 3-5} \mathrm{CKO}$ mice (Fig. 1). Trigeminal afferent patterns corresponding to the barrelettes in the PrV were indistinguishable from those seen in the control mice. The usual numbers of whisker follicles and their patterned arrangement were also present on the snout. In contrast, there were duplicate barreloids and barrel patterns in the VPM and cortex, respectively, as shown recently (Renier et al., 

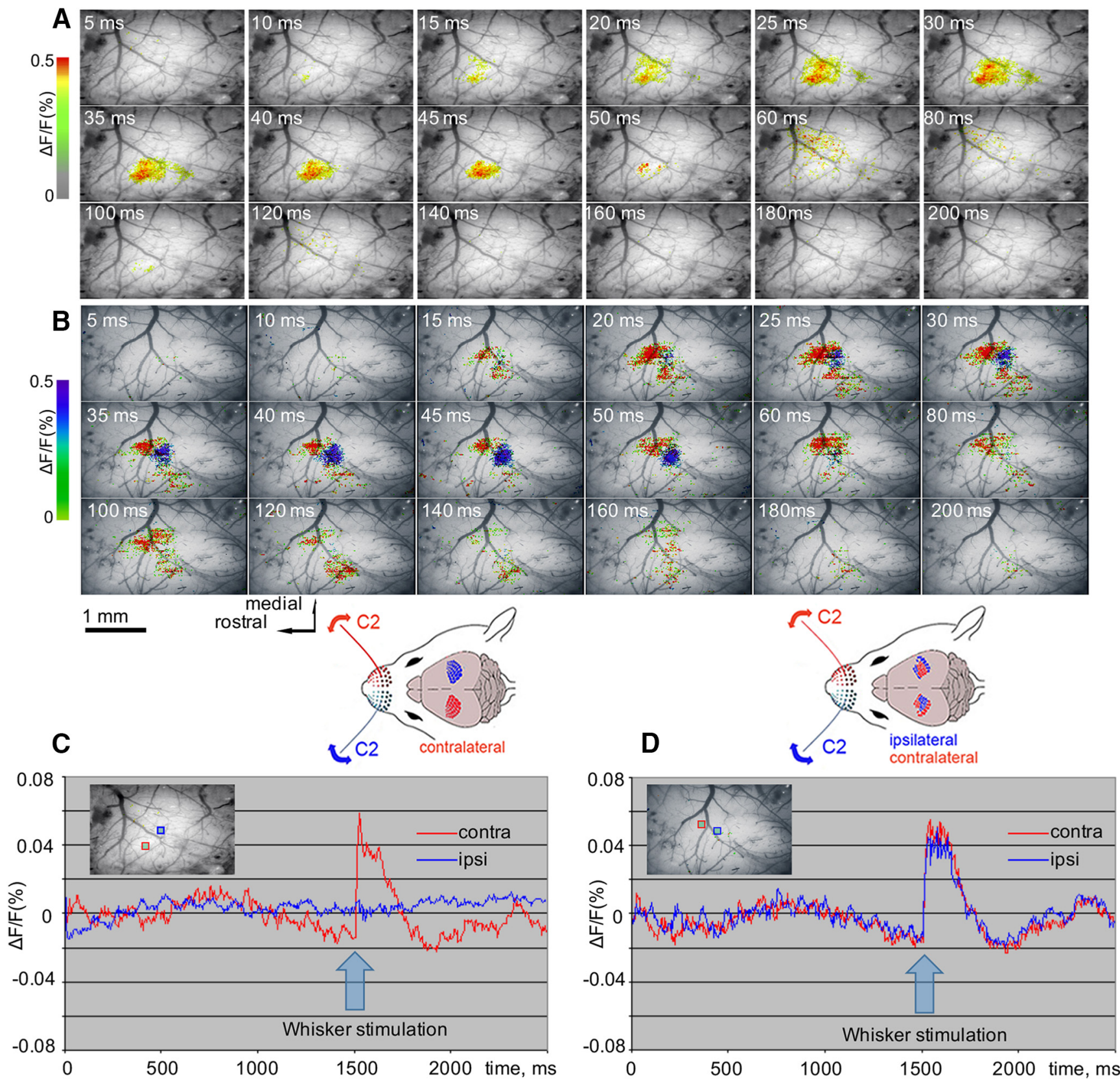

Figure 2. VSD imaging in barrel cortex after C 2 whisker stimulation. $A$, Pseudocolor map of the responses in the barrel cortex to contralateral $C 2$ stimulation. $B$, Pseudocolor map of the ipsilateral (blue) and contralateral (red) responses in the left hemisphere in a $R o b 03^{R 3-5} \mathrm{CKO}$ mouse. The time after stimulus onset is at the top left corner of each plate. $C, D$, The time course of the integrated fluorescence signals (blue represents ipsilateral; red represents contralateral) calculated in the squares $\left(7 \times 7\right.$ pixels) in insets at $40 \mathrm{~ms}$ image in control $(\boldsymbol{C})$ and $R o b 03^{R 3-5} \mathrm{CKO}$ case $(\boldsymbol{D})$. To visualize the color-coded squares, pseudocolor-coded responses are filtered, the unfiltered images are seen in $40 \mathrm{~ms}$ response images in $\boldsymbol{A}$ and $\boldsymbol{B}$.

2017). Selective labeling with lipophilic tracers and activitydependent immediate early gene (c-Fos) expression identified ipsilateral and contralateral individual whisker or whisker row representations in the barrel cortex (Renier et al., 2017). The present immunohistochemistry and histological assays confirmed the thalamic and cortical pattern defects.

VSDi is a convenient approach to map cortical activity following sensory stimulation. We applied voltage-sensitive dye RH1691 to the barrel cortex and stimulated the second whisker in row C (C2) on the snout. Thereinafter, we imaged the cortical activity. In control animals only contralateral whisker stimulation elicited VSD signals in a given cortex, whereas ipsilateral stimulation did not evoke any notable activity during the imaging time frame (Fig. 2). In contrast to the control mice, in all imaged mutant animals, there were responses to stimulation of both the ipsilateral and contralateral C2 whiskers (Fig. 2). The distance between centers of activity patterns, elicited by ipsilateral and contralateral stimulation, was on the average $0.4 \pm 0.1 \mathrm{~mm}$, which is in line with the morphological data using immunohistochemistry or CO histochemistry.

As seen in Figure 2, activated cortical areas show a shift in time and are larger than those seen with histochemical markers. That is in part due to the imaging approach, and in part the spread of activity from layer IV to supragranular layers over time. It is noteworthy that the time courses of responses to ipsilateral and contralateral whisker stimulation were not different. 
Following confirmation of morphological and functional representations of the whiskers bilaterally in the thalamocortical pathway, we used a battery of sensorimotor tests to determine how bifacial maps in the forebrain would affect the behavior of the animal. We found that the general physical strength of the Robo ${ }^{R 3-5} \mathrm{CKO}$ mice appeared normal in the grip test $\left(t_{(16)}=\right.$ $0.022, p=0.9827$ ).

General paw tactile sensation also appeared normal in Robo $3^{R 3-5} \mathrm{CKO}$ mice. The latencies of licking the hindpaw to rid it of the adhesive paper were similar in the experimental and control groups $\left(t_{(16)}=0.4954, p=0.627\right)$. This observation indicates that, functionally, the dorsal column lemniscal pathway is not affected, as expected from unaltered patterning and size of the paw maps in the brainstem, thalamus, and cortex.

Spontaneous alternation ratio in a Y-maze was significantly lower in $R o b o 3^{R 3-5} c K O$ mice $(51.11 \pm 3.98 \%)$ than in Robo ${ }^{\text {lox } / l o x}$ mice $(70.56 \pm 2.42 \%)\left(t_{(16)}=4.17585, p=0.0007\right)$. The test is generally used as a measure of rodent cognitive function. The animals have to remember and recognize the shape of the Y-maze, and which arm was visited last, and they will naturally enter the most number of arms in a given trial. Because whiskers are very important in exploratory behavior of mice, we used this test to determine whether bifacial barrel maps would affect spatial discrimination. Indeed, a lower performance in $R o b o 3^{R 3-5} \mathrm{CKO}$ mice indicates that bilateral whisker representation in the thalamocortical pathway impairs spatial discrimination and possibly cognitive functions.

In the open field test, we recorded the behavior of the mice to assess their exploratory behavior, rather than their general activity level. In this test, Robo $3^{R 3-5} \mathrm{cKO}$ mice showed a significant increase in locomotion $(118.67 \pm 22.53)$ compared with that of controls $(16.44 \pm 2.20)\left(t_{(8)}=4.516, p=0.002\right)$. But we noted no differences in "risk assessment behaviors," such as stretch-attend postures $\left(t_{(11)}=0.264, p=0.7966\right)$. We also tested social behaviors in the open field chamber where the subject mouse was confronted with an unfamiliar (intruder) male mouse. We recorded social contacts and flight responses. There were no significant differences in duration of social contacts $\left(t_{(11)}=0.1602, p=\right.$ 0.8755 ) or flight response (to a frontal approach; $t_{(8)}=1.4944$, $p=0.1734$, and to a back approach; $t_{(12)}=0.695, p=0.5001$ ).

The horizontal surface approach test can be used for measuring whisker sense and body coordination. In this test, $R o b o 3^{R 3-5} \mathrm{CKO}$ mice exhibited significantly shorter distance $(3.77 \pm 0.26 \mathrm{~cm})$ to reach the edge surface than control mice $\left(4.58 \pm 0.26 \mathrm{~cm} ; t_{(16)}=\right.$ $2.1829, p=0.0433)$, which indicates impairment in whisker sensation. A similar impairment in $\mathrm{Robo}^{R 3-5} \mathrm{CKO}$ mice was found in other tests that require whisker sensation. In the bridge crossing test, Robo $3^{R 3-5} \mathrm{CKO}$ mice took longer time to cross the bridge on the first trial compared with control mice $(58.00 \pm 11.07 \mathrm{~s}$ vs $22.78 \pm 4.90$ s) (gene: $F_{(1,16)}=5.64, p<0.05$; trial: $F_{(2,32)}=$ 15.71, $p<0.01$; and gene $\times$ trial: $F_{(2,32)}=6.54, p<0.01$; Trial 1 , $\left.F_{(1,16)}=8.47, p<0.05\right)$. In the swimming test, $R o b o 3^{R 3-5} c K O$ mice exhibited significantly shorter floating time $(5.59 \pm 1.51 \mathrm{~s})$ compared with control mice $(31.67 \pm 2.75 \mathrm{~s})\left(t_{(16)}=8.31, p<\right.$ 0.0001 ), while they exhibited a similar level of struggling time $(32.85 \pm 5.30 \mathrm{~s})$ as control mice $(22.67 \pm 2.14 \mathrm{~s})\left(t_{(11)}=1.78\right.$, $p=0.102)$.

The Robo ${ }^{R 3-5} \mathrm{CKO}$ mice have full sets of whiskers and show whisking behavior. We recorded the whisking behaviors with a high-speed camera (120 fps). We measured the frequencies and types of whisking when mice freely whisked in the air and at an object they encountered. We found that mice tended to show symmetry whisking (horizontal movement in all directions) when they do not contact an object, and active whisking (bundled and forward oriented movement with high frequency) toward an object. Robo $3^{R 3-5} \mathrm{CKO}$ mice show a lower ratio of active whisking $(0.6307 \pm 0.0419)$ during whisking surfaces of objects compared with that of the controls $(0.8394 \pm 0.0472)\left(t_{(16)}=3.3076, p=\right.$ $0.0044)$. Control mice displayed faster frequencies in active whisking than symmetry whisking, whereas $R o b o 3^{R 3-5} c K O$ mice showed similar lower frequencies of whisking in both symmetry and active whisking.

The gap-crossing test is one of the few established tests for whisker-barrel function in rodents, and it is conducted under infrared lighting to eliminate visual cues. We found that $\mathrm{Robo}^{\mathrm{R} 3-5} \mathrm{CKO}$ mice crossed shorter $(3.00 \pm 0.24 \mathrm{~cm})$ gap distances than controls $(4.11 \pm 0.35 \mathrm{~cm})\left(t_{(16)}=4.718, p=0.0002\right)$. We further investigated sensory performance with an object shape recognition test, which relies in part on vision, and a texture discrimination test, which relies on whisker sensation. In both of these tests (Fig. 3), two identical objects were presented in the home cage on Trial 1. On Trials 2 and 3, one of these objects was removed and a novel object was introduced. If mice recognize the difference between the objects they spend more time exploring the novel one. Thus, the score of novel object preference would be higher than the $50 \%$ chance level. Mice were able to see the objects visually in the object shape recognition test, but they are not allowed to see the shape in the texture discrimination test, as this test was conducted under infrared light. Both Robo ${ }^{R 3-5} \mathrm{cKO}$ mice and control mice displayed a clear discrimination on Trials 2 and 3 in the shape recognition test (gene: $F_{(1,16)}=0.003$, not significant; trial: $F_{(2,32)}=37.44, p<0.01$; gene $\times$ trial: $F_{(2,32)}=1.36$, not significant). On the other hand, Robo $3^{R 3-5} \mathrm{cKO}$ mice did not show preference on Trials 2 and 3 in the texture recognition test, whereas control mice exhibited clear signs of discrimination (gene: $F_{(1,16)}=20.24, p<0.01$; trial: $F_{(2,32)}=8.52, p<0.01$; gene $\times$ trial: $F_{(2,32)}=3.76, p<0.05$; Trial 1: $F_{(1,16)}=0.48$, not significant; Trial 2: $F_{(1,16)}=12.18, p<0.01 ;$ Trial 3: $F_{(1,16)}=9.62$, $p<0.01$ ) (Fig. 3). These data clearly indicate that $R_{0 b o} 3^{R 3-5} c K O$ mice distinguish object shape novelty using visual cues, but not object texture by whisker-related tactile cues.

In a whisking laterality test, $R o b o 3^{R 3-5} \mathrm{cKO}$ mice detected the rods along the bridge similar to the control animals $\left(t_{(7)}=\right.$ $0.09827, p=0.9245$; Fig. 3B). Upon encountering a rod, control mice showed active whisking with a medial approach or on the ipsilateral side with respect to the rod, whereas $R o b o 3^{R 3-5} \mathrm{cKO}$ mice mostly whisked the contralateral side to investigate the rod (ipsilateral: $t_{(14)}=0.701158, p=0.4947$; medial: $t_{(14)}=9.0911$, $p<0.0001$; and contralateral: $t_{(7)}=24.677, p<0.0001$ ) (Fig. 3).

\section{Discussion}

Whisker-specific neural patterns depend on an intact sensory periphery during a critical period in development (for review, see Erzurumlu and Gaspar, 2012). Spontaneous mutation or experimental induction of extra whisker follicles on the snout causes formation of corresponding additional barrels and subcortical whisker neural modules (Welker and Van der Loos, 1986; Ohsaki et al., 2002). At the other end of the spectrum, alterations in molecular signals, intrinsic to the developing neocortex, can also dramatically alter the positioning and size, even leading to the duplication of the barrel fields (Fukuchi-Shimogori and Grove, 2001; Shimogori et al., 2004; Assimacopoulos et al., 2012; Zembrzycki et al., 2013). We recently reported that axon pathfinding errors in subcortical connections, such as those between the PrV and VPM, create pattern deficits in whisker maps as well (Renier et al., 2017). In Robo $3^{R 3-5} c K O$ mice, contralateralization defects 
Object Discrimination Test (in dim light)

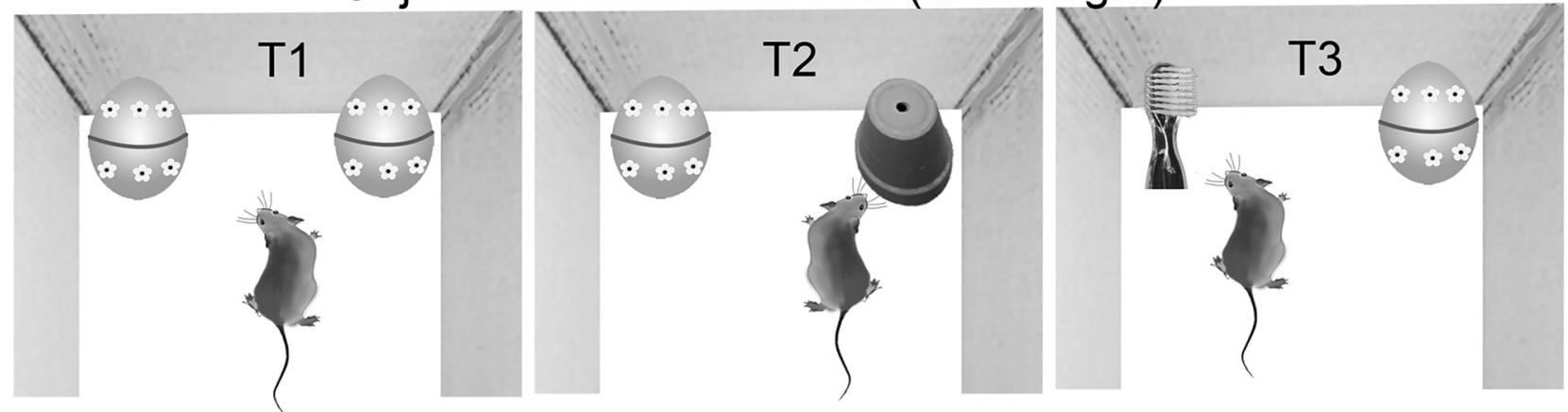

Texture Discrimination Test (in infrared light)
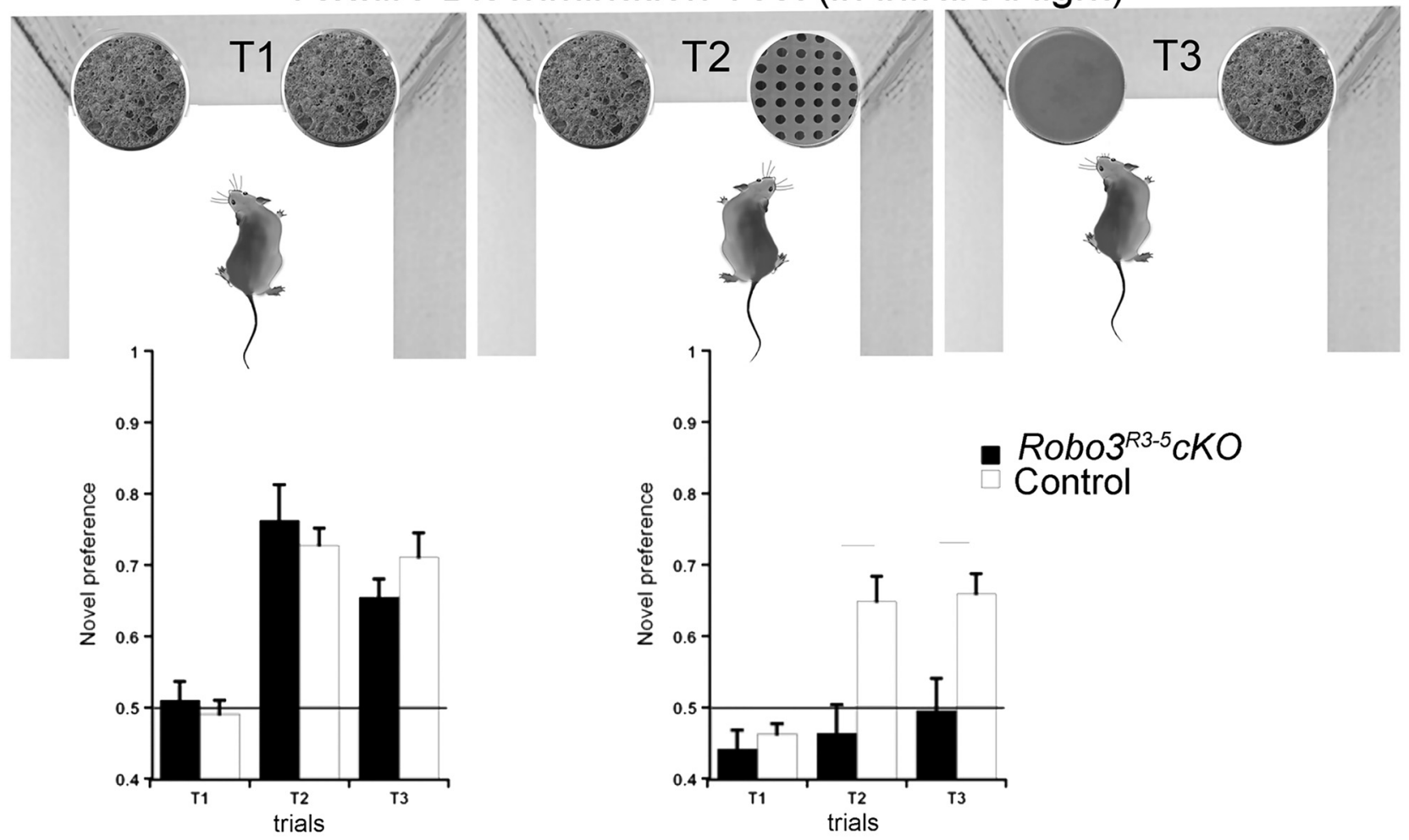

Object Discrimination

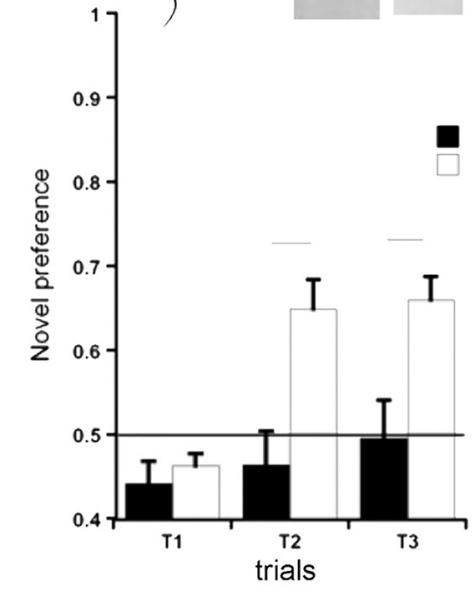

Robo3 ${ }^{\text {R3-5 }} \mathrm{CKO}$

Control

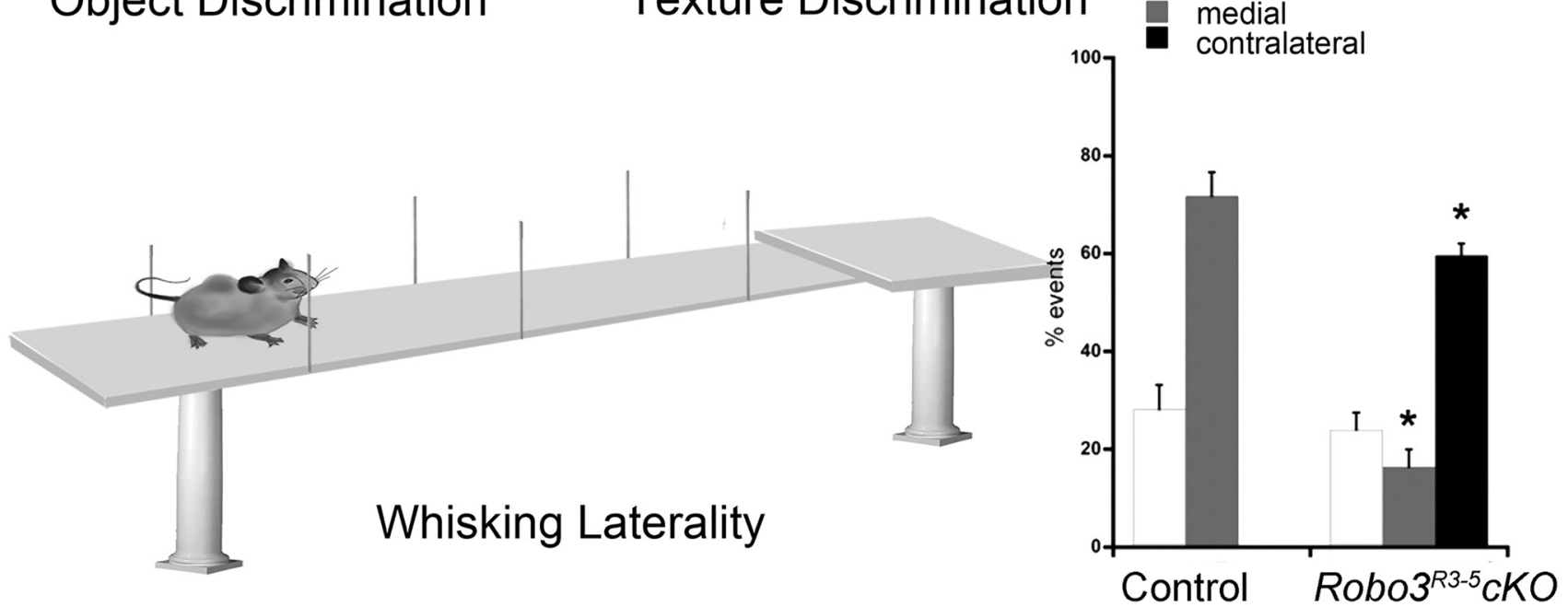

Figure 3. Object and texture recognition and whisking laterality tests. In object recognition test, two identical objects (an Easter egg) were presented in opposite corners of the cage and mice were allowed to freely investigate them during Trial 1 (T1). In Trial 2 (T2), one of the objects was removed and replaced with a novel object (small flower pot). In Trial 3 (T3), one object from the first trial (Easter egg) and yet another novel object (toothbrush) were presented. Normally, mice spend more time sniffing and whisking at the new object. (Figure legend continues.) 
of the trigeminothalamic pathway lead to crowding of bilateral whisker-related neural modules in the face representation areas of the VPM and the SI cortex. In both areas, the size, orientation, and positioning of the face representations do not seem to be altered. Also, there are no effects on the surrounding paw and body representation areas. Thus, in accordance with the studies cited above, the size, orientation, and positioning of sensory maps are most likely determined by intrinsic molecular cues. Here, we show that the bilateral whisker maps are active and influence sensorimotor behaviors.

In the Robo ${ }^{R 3-5} \mathrm{CKO}$ cortex, individual barrels are notably smaller and the ipsilateral barrel map inserts itself inside the contralateral barrel map, without any overlap. The ipsilateral and contralateral whiskers have their distinct barrels that do not neighbor each other. This brings out a distinct contrast to the visual system, where ipsilateral and contralateral visual inputs that are in register with respect to the sensory space converge on to the layer IV cells and eventually lead to the perception of depth. The visual system, too, has a number of mutations that affect contralateralization. Midline crossing defects of the optic nerve lead to significant alterations in retinotopic and eye-specific maps, most notably in the visual cortex. In the human visual pathway, nasal retinal axons cross the midline at the chiasm while temporal retinal axons do not, yielding $\sim 50 \%$ crossing of retinal axons from each eye. In albinism, part of the temporal retinal axons also cross at the chiasm leading to a partially overlaid representation of opposing visual fields in the primary visual cortex. Visual perception remains relatively intact, but this condition of partial map duplication is accompanied by optokinetic nystagmus, reduced visual acuity, and binocular vision, among other symptoms (Creel et al., 1990). In an achiasma condition, all retinal axons project to the ipsilateral hemisphere leading to overlay of nasal and temporal hemiretinae maps in primary visual cortex. Recent imaging studies show that, within the overlapping maps, projections from the nasal and temporal retina are interdigitated, much like ocular dominance columns. Binocular interactions are only seen in higher cortical visual fields, such as V5 and fusiform gyrus (Hoffmann et al., 2012; Davies-Thompson et al., 2013; Olman et al., 2016). As in albinism, despite reduced visual acuity and depth perception, overall visual perception remains intact. This is most likely due to corticocortical compensatory interactions. Several previous studies on albino and achiasmatic animals have described mapping defects and physiological consequences (Guillery, 1971; Guillery and Kaas, 1973; Cucchiaro and Guillery, 1984; Guillery et al., 1984; Williams et al., 1994; Hogan et al., 1999). The present Robo ${ }^{R 3-5}$ cKO somatosensory phenotype in-

\section{$\leftarrow$}

(Figure legend continued.) In this experiment, mice were allowed to use visual cues. The texture discrimination test was conducted the same way but under infrared lighting, and the object shapes were the same but they all had different textures. Significant differences between the control and $\mathrm{Robo}^{R 3-5} \mathrm{CKO}$ mice were found on $\mathrm{T} 1$ and $\mathrm{T} 2$ only in the texture discrimination test. In the whisking laterality test, there was no significant difference in rod detection between the control and cKO mice $\left(t_{(7)}=0.09827, p=0.9245\right)$. When mice oriented their snout and left or right set of whiskers to the rod, significant differences in laterality were observed. "Ipsilateral" indicates that the mouse whisked the same side of whiskers at a rod located on the same side (e.g., left side rod, left whiskers). "Medial" indicates that the mouse oriented its snout to the rod. "Contralateral" indicates that the mouse oriented the opposite side of whiskers to a rod located at one side (e.g., left side rod, right whiskers). Control mice tended to use the medial approach or ipsilateral whiskers to investigate a rod, whereas $R o b 03^{R 3-5} \mathrm{CKO}$ mice tended to use the contralateral set of whiskers to explore the rod (lateral: $t_{(14)}=0.701158, p=0.4947$; medial: $t_{(14)}=9.0911, p<0.0001$; and contralateral: $\left.t_{(7)}=24.677,{ }^{*} p<0.0001\right)$. Data are mean \pm SEM. troduces a different map layout as a consequence of bilateral trigeminothalamic projections. Here the two face maps with rows of whisker-representing modules are squeezed into separate zones of a normal size face map area. Interestingly, the ipsilateral face map is nestled inside a split contralateral face map. Overall, individual barrels representing the same whisker on both sides are distant from one another. Because the barrels are activated by stimulation of ipsilateral or contralateral whiskers, overall cortical whisker perception should be present. However, due to the reduced size of individual whisker barrels and/or activation of the barrel cortex from both sides of the face, sensory acuity and discrimination are impaired.

Sensory maps of the neocortex form close functional relations with the association and motor cortices; moreover, all this circuitry is in intimate relation with the motivational and cognitive circuitries of the brain. The Robo $3^{R 3-5} \mathrm{cKO}$ mouse model offers a means to explore how a significant change in a major sensory map in the cortex may affect the rest of the brain circuitry and consequently the behavioral repertoire of the animal. The results of the sensorimotor tests in $\mathrm{Robo}^{\mathrm{R3}-5} \mathrm{CKO}$ mice do not show notable motor defects, except those that involve whisker sensation. We do not yet know how duplicate maps in the barrel cortex alters other associated cortical circuitry such as the callosal, S1 to $\mathrm{M} 1$ and corticocortical involving supragranular layers, or for that matter, even infragranular layers that project to the VPM and brainstem trigeminal centers. An MRI study found that the size and the connectivity of the corpus callosum appeared normal in an achiasma case (Davies-Thompson et al., 2013). If afferent projections to a given target follow "chemoaffinity," or intrinsic molecular guidance cues, the other somatosensory-related projections in in Robo $^{R 3-5} \mathrm{CKO}$ mice should not be affected. Perhaps the similar organization of the whisker map in the VPM and in the barrel cortex is indicative of intrinsic wiring cues. Nevertheless, we do not know how partial crossing of trigeminothalamic projections lead to an ipsilateral map, carving an ipsilateral territory within the contralateral map. This collateralization defect in the sensory thalamus is quite unlike that which is seen in retinal projections to the LGN of achiasmatic dogs (Williams et al., 1994; Hogan et al., 1999).

Differences in exploratory versus discriminative whisking behaviors of $R o b o 3^{R 3-5} \mathrm{CKO}$ mice suggest that exploratory, passive whisking is mediated through unaffected brainstem circuits involving trigeminofacial connections between the spinal trigeminal subnucleus caudalis and the facial nucleus. Active, discriminative whisking most likely requires sensorimotor integration at higher centers; bilateral whisker maps and smaller whiskerrelated neural modules in the thalamus and cortex interfere with this process.

Like the somatosensory pathway, the descending motor pathway is largely crossed. Motor commands from the cortex reach the contralateral facial nucleus in the brainstem, the lateral subnuclei of which control facial muscles used in whisking. In its normal operation, when both the ascending tactile sensory and descending motor pathways are crossed, they interact synergistically. When one of these systems has midline crossing defects, the synergistic activity is disrupted. There are examples of such crossing defects in humans as well, such as congenital mirror movement disorder and horizontal gaze palsy with progressive scoliosis. These midline crossing defects have been linked to mutations in DCC and Robo3 receptors, respectively (Jen et al., 2004; Nugent et al., 2012; Chédotal, 2014; Meneret et al., 2015; Friocourt and Chédotal, 2017). The peculiar tendency of the Robo $3^{R 3-5} \mathrm{cKO}$ mice to use contralateral whiskers when they encounter an object on the left 
or right side of the snout in the laterality test could perhaps could be explained by conflicting sensory and motor activity.

In the presence of visual cues, $R o b o 3^{R 3-5} \mathrm{CKO}$ mice distinguish object shape novelty but perform poorly when they are challenged to discriminate object textures relying on their whiskers and without visual cues. Our laboratories have observed impaired performance in whisker-related tasks in common laboratory mice following clipping of all their whiskers (Arakawa and Erzurumlu, 2015), and in a variety of genetically altered mouse lines that have barrel cortex or thalamic pattern deficits. So far, these have included mice that lack functional thalamus-specific RIM proteins involved in neurotransmitter release at the thalamocortical synapse (Narboux-Nême et al., 2012), Adenylate cyclase Type I gene $A C 1$ and thalamus-specific $A C 1$ null mice that lack barrels (Arakawa et al., 2014a), thalamus-specific Grin 1 null mice that lack thalamic patterns (Arakawa et al., 2014b). Whether whisker clipped, or with absent or aberrant thalamic, cortical axonal/cellular neural patterns, whisker-related behavioral performance is impaired in varying degrees. $\mathrm{Robo}^{R 3-5} \mathrm{CKO}$ mice differ from these previous mouse phenotypes such that the whisker patterns are not abolished but emerge as bilateral representations. This model offers unique opportunities to investigate how increased numbers of barrels representing both sides of the snout connect to the rest of the brain circuitry and, moreover, whether barrel size is an important factor in sensory acuity. Perhaps selectively silencing inputs from the PrV on one side will allow us to determine similarities and differences between ipsilateral and contralateral whisker maps in the cortex.

\section{References}

Arakawa H, Erzurumlu RS (2015) Role of whiskers in sensorimotor development of C57BL/6 mice. Behav Brain Res 287:146-155. CrossRef Medline

Arakawa H, Akkentli F, Erzurumlu RS (2014a) Region-specific disruption of adenylate cyclase type 1 gene differentially affects somatosensorimotor behaviors in mice. eNeuro 1:ENEURO.0007-14.2014. CrossRef Medline

Arakawa H, Suzuki A, Zhao S, Tsytsarev V, Lo FS, Hayashi Y, Itohara S, Iwasato T, Erzurumlu RS (2014b) Thalamic NMDA receptor function is necessary for patterning of the thalamocortical somatosensory map and for sensorimotor behaviors. J Neurosci 34:12001-12014. CrossRef Medline

Assimacopoulos S, Kao T, Issa NP, Grove EA (2012) Fibroblast growth factor 8 organizes the neocortical area map and regulates sensory map topography. J Neurosci 32:7191-7201. CrossRef Medline

Barnéoud P, Gyger M, Andrés F, van der Loos H (1991) Vibrissa-related behavior in mice: transient effect of ablation of the barrel cortex. Behav Brain Res 44:87-99. CrossRef Medline

Bechara A, Laumonnerie C, Vilain N, Kratochwil CF, Cankovic V, Maiorano NA, Kirschmann MA, Ducret S, Rijli FM (2015) Hoxa2 selects barrelette neuron identity and connectivity in the mouse somatosensory brainstem. Cell Rep 13:783-797. CrossRef Medline

Blanchard DC, Griebel G, Blanchard RJ (2003) The Mouse Defensive Test Battery: pharmacological and behavioral assays for anxiety and panic. Eur J Neurosci 463:97-116. CrossRef Medline

Bouet V, Boulouard M, Toutain J, Divoux D, Bernaudin M, Schumann-Bard P, Freret T (2009) The adhesive removal test: a sensitive method to assess sensorimotor deficits in mice. Nat Protoc 4:1560-1564. CrossRef Medline

Brooks SP, Dunnett SB (2009) Tests to assess motor phenotype in mice: a user's guide. Nat Rev Neurosci 10:519-529. CrossRef Medline

Chédotal A (2011) Further tales of the midline. Curr Opin Neurobiol 21: 68-75. CrossRef Medline

Chédotal A (2014) Development and plasticity of commissural circuits: from locomotion to brain repair. Trends Neurosci 37:551-562. CrossRef Medline

Chiaia NL, Bennett-Clarke CA, Rhoades RW (1991) Effects of cortical and thalamic lesions upon primary afferent terminations, distributions of projection neurons, and the cytochrome oxidase pattern in the trigeminal brainstem complex. J Comp Neurol 303:600-616. CrossRef Medline

Crawley JN (1999) Behavioral phenotyping of transgenic and knockout mice: experimental design and evaluation of general health, sensory functions, motor abilities, and specific behavioral tests. Brain Res 835:18-26. CrossRef Medline

Crawley JN (2008) Behavioral phenotyping strategies for mutant mice. Neuron 57:809-818. CrossRef Medline

Creel DJ, Summers CG, King RA (1990) Visual anomalies associated with albinism. Ophthalmic Paediatr Genet 11:193-200. CrossRef Medline

Cucchiaro J, Guillery RW (1984) The development of the retinogeniculate pathways in normal and albino ferrets. Proc R Soc Lond B Biol Sci 223: 141-164. CrossRef Medline

Davies-Thompson J, Scheel M, Jane Lanyon L, Sinclair Barton JJ (2013) Functional organisation of visual pathways in a patient with no optic chiasm. Neuropsychologia 51:1260-1272. CrossRef Medline

Deacon RM (2013) Measuring motor coordination in mice. J Vis Exp 75: 2609. CrossRef

Erzurumlu RS, Ebner FF (1988) Maintenance of discrete somatosensory maps in subcortical relay nuclei is dependent on an intact sensory cortex. Brain Res Dev Brain Res 44:302-308. Medline

Erzurumlu RS, Gaspar P (2012) Development and critical period plasticity of the barrel cortex. Eur J Neurosci 35:1540-1553. CrossRef Medline

Erzurumlu RS, Jhaveri S (1990) Thalamic axons confer a blueprint of the sensory periphery onto the developing rat somatosensory cortex. Brain Res Dev Brain Res 56:229-234. CrossRef Medline

Erzurumlu RS, Murakami Y, Rijli FM (2010) Mapping the face in the somatosensory brainstem. Nat Rev Neurosci 11:252-263. CrossRef Medline

Ferezou I, Bolea S, Petersen CC (2006) Visualizing the cortical representation of whisker touch: voltage-sensitive dye imaging in freely moving mice. Neuron 50:617-629. CrossRef Medline

Friocourt F, Chédotal A (2017) The Robo3 receptor, a key player in the development, evolution and function of commissural systems. Dev Neurobiol 77:876-890. CrossRef Medline

Fukuchi-Shimogori T, Grove EA (2001) Neocortex patterning by the secreted signaling molecule FGF8. Science 294:1071-1074. CrossRef Medline

Gerlai R, Thibodeaux H, Palmer JT, van Lookeren Campagne M, Van Bruggen N (2000) Transient focal cerebral ischemia induces sensorimotor deficits in mice. Behav Brain Res 108:63-71. CrossRef Medline

Guillery RW (1971) An abnormal retinogeniculate projection in the albino ferret (Mustela furo). Brain Res 33: 482-485. CrossRef Medline

Guillery RW, Kaas JH (1973) Genetic abnormality of the visual pathways in a "white" tiger. Science 180:1287-1289. CrossRef Medline

Guillery RW, Hickey TL, Kaas JH, Felleman DJ, Debruyn EJ, Sparks DL (1984) Abnormal central visual pathways in the brain of an albino green monkey (Cercopithecus aethiops). J Comp Neurol 226:165-183. CrossRef Medline

Hoffmann MB, Kaule FR, Levin N, Masuda Y, Kumar A, Gottlob I, Horiguchi H, Dougherty RF, Stadler J, Wolynski B, Speck O, Kanowski M, Liao YJ, Wandell BA, Dumoulin SO (2012) Plasticity and stability of the visual system in human achiasma. Neuron 75:393-401. CrossRef Medline

Hogan D, Garraghty PE, Williams RW (1999) Asymmetric connections, duplicate layers, and a vertically inverted map in the primary visual system. J Neurosci 19:RC38. Medline

Hutson KA, Masterton RB (1986) The sensory contribution of a single vibrissa's cortical barrel. J Neurophysiol 56:1196-1223. Medline

Iwasato T, Erzurumlu RS, Huerta PT, Chen DF, Sasaoka T, Ulupinar E, Tonegawa S (1997) NMDA receptor-dependent refinement of somatotopic maps. Neuron 19: 1201-10. CrossRef Medline

Izzi L, Charron F (2011) Midline axon guidance and human genetic disorders. Clin Genet 80:226-234. CrossRef Medline

Jen JC, Chan WM, Bosley TM, Wan J, Carr JR, Rub U, Shattuck D, Salamon G, Kudo LC, Ou J, Lin DD, Salih MA, Kansu T, Al Dhalaan H, Al Zayed Z, MacDonald DB, Stigsby B, Plaitakis A, Dretakis EK, Gottlob I, et al. (2004) Mutations in a human ROBO gene disrupt hindbrain axon pathway crossing and morphogenesis. Science 304:1509-1513. CrossRef Medline

Killackey HP, Fleming K (1985) The role of the principal sensory nucleus in central trigeminal pattern formation. Brain Res 354:141-145. Medline

Komotar RJ, Kim GH, Sughrue ME, Otten ML, Rynkowski MA, Kellner CP, Hahn DK, Merkow MB, Garrett MC, Starke RM, Connolly ES (2007) 
Neurologic assessment of somatosensory dysfunction following an experimental rodent model of cerebral ischemia. Nat Protoc 2:2345-2347. CrossRef Medline

Koolhaas JM, Coppens CM, de Boer SF, Buwalda B, Meerlo P, Timmermans PJA (2013) The Resident-Intruder Paradigm: a standardized test for aggression, violence and social stress. J Vis Exp 77:4367. CrossRef Medline

Lo FS, Akkentli F, Tsytsarev V, Erzurumlu RS (2013) Functional significance of cortical NMDA receptors in somatosensory information processing. J Neurophysiol 110:2627-2636. CrossRef Medline

Ma PM, Woolsey TA (1984) Cytoarchitectonic correlates of the vibrissae in the medullary trigeminal complex of the mouse. Brain Res 306:374-379. CrossRef Medline

Meneret A, Trouillard O, Brochard V, Roze E (2015) Congenital mirror movements caused by mutation in the DCC gene. Dev Med Child Neurol 57:776. CrossRef Medline

Mirza R, Kivrak BG, Erzurumlu RS (2013) Cooperative slit and netrin signaling in contralateralization of the mouse trigeminothalamic pathway. J Comp Neurol 521:312-325. CrossRef Medline

Mothes HK, Opitz B, Werner R, Clausing P (1996) Effects of prenatal ethanol exposure and early experience on home-cage and open-field activity in mice. Neurotoxicol Teratol 18:59-65. CrossRef Medline

Narboux-Nême N, Evrard A, Ferezou I, Erzurumlu RS, Kaeser PS, Lainé J, Rossier J, Ropert N, Südhof TC, Gaspar P (2012) Neurotransmitter release at the thalamocortical synapse instructs barrel formation but not axon patterning in the somatosensory cortex. J Neurosci 32:6183-6196. CrossRef Medline

Nawabi H, Castellani V (2011) Axonal commissures in the central nervous system: how to cross the midline? Cell Mol Life Sci 68:2539-2553. CrossRef Medline

Nugent AA, Kolpak AL, Engle EC (2012) Human disorders of axon guidance. Curr Opin Neurobiol 22:837-843. CrossRef Medline

Ohsaki K, Osumi N, Nakamura S (2002) Altered whisker patterns induced by ectopic expression of Shh are topographically represented by barrels. Brain Res Dev Brain Res 137:159-170. CrossRef Medline

Olman CA, Bao P, Engel SA, Grant AN, Purington C, Qiu C, Schallmo MP, Tjan BS (2016) Hemifield columns co-opt ocular dominance column structure in human achiasma. Neuroimage. Advance online publication. Retrieved Dec. 23, 2016. doi: 10.1016/j.neuroimage.2016.12.063. CrossRef Medline

Oury F, Murakami Y, Renaud JS, Pasqualetti M, Charnay P, Ren SY, Rijli FM (2006) Hoxa2- and rhombomere-dependent development of the mouse facial somatosensory map. Science 313:1408-1413. CrossRef Medline
Renier N, Dominici C, Erzurumlu RS, Kratochwil CF, Rijli FM, Gaspar P, Chédotal A (2017) A mutant with bilateral whisker to barrel inputs unveils somatosensory mapping rules in the cerebral cortex. Elife 6:e23494. CrossRef Medline

Rodgers RJ, Dalvi A (1997) Anxiety, defence and the elevated plus-maze. Neurosci Biobehav Rev 21:801-810. CrossRef Medline

Saitoh A, Ohashi M, Suzuki S, Tsukagoshi M, Sugiyama A, Yamada M, Oka J, Inagaki M, Yamada M (2014) Activation of the prelimbic medial prefrontal cortex induces anxiety-like behaviors via $\mathrm{N}$-methyl-D-aspartate receptor-mediated glutamatergic neurotransmission in mice. J Neurosci Res 92:1044-1053. CrossRef Medline

Schneider-Maunoury S, Topilko P, Seitandou T, Levi G, Cohen-Tannoudji M, Pournin S, Babinet C, Charnay P (1993) Disruption of Krox-20 results in alteration of rhombomeres 3 and 5 in the developing hindbrain. Cell 75:1199-1214. CrossRef Medline

Shimogori T, Banuchi V, Ng HY, Strauss JB, Grove EA (2004) Embryonic signaling centers expressing BMP, WNT and FGF proteins interact to pattern the cerebral cortex. Development 131:5639-5647. CrossRef Medline

Tsytsarev V, Pope D, Pumbo E, Yablonskii A, Hofmann M (2010) Study of the cortical representation of whisker directional deflection using voltagesensitive dye optical imaging. Neuroimage 53:233-238. CrossRef Medline

Van Der Loos H (1976) Barreloids in mouse somatosensory thalamus. Neurosci Lett 2:1-6. CrossRef Medline

Welker E, Van der Loos H (1986) Quantitative correlation between barrelfield size and the sensory innervation of the whiskerpad: a comparative study in six strains of mice bred for different patterns of mystacial vibrissae. J Neurosci 6:3355-3373. Medline

Williams RW, Hogan D, Garraghty PE (1994) Target recognition and visual maps in the thalamus of achiasmatic dogs. Nature 367:637-639. CrossRef Medline

Wolf A, Bauer B, Abner EL, Ashkenazy-Frolinger T, Hartz AM (2016) A comprehensive behavioral test battery to assess learning and memory in 129S6/Tg2576 mice. PLoS One 11:e0147733. CrossRef Medline

Woolsey TA, Van der Loos H (1970) The structural organization of layer IV in the somatosensory region (SI) of mouse cerebral cortex: the description of a cortical field composed of discrete cytoarchitectonic units. Brain Res 17:205-242. CrossRef Medline

Zembrzycki A, Chou SJ, Ashery-Padan R, Stoykova A, O’Leary DD (2013) Sensory cortex limits cortical maps and drives top-down plasticity in thalamocortical circuits. Nat Neurosci 16:1060-1067. CrossRef Medline 